\title{
Energy Management System Connected for Microgrid using Fuzzy Logic Algorithm
}

\author{
S.Vidyasagar, R. Ramya, V.Kalyanasundaram, George Fernandez.S, Rishikesh Jha, Umesh \\ Pratap Sahu, Prachi Naladkar
}

\begin{abstract}
In this paper, energy control procedure is designed for the lattice associated combined energy stockpiling with the cell and the supercapacitor under various working ways. The primary points of interest in the recommended EMS are efficacious power sharing among the different energy stockpiling system. The viability of the suggested technique are supported by both simulation and trail studies.
\end{abstract}

Keywords - Energy Management Scheme (EMS), Hybrid Energy Storage (HESS), battery, supercapacitors, power sharing, simulation, experimental studies.

\section{INTRODUCTION}

The usage of the shared inexhaustible powers like the wind and photovoltaic(PV), in the dispensation network is being becoming greater over a period. With increased awareness of environmental destruction caused due to elevated carbon dioxide, released from fossil fuel power generation, usage of inexhaustible energy has become objective for energy generation [1]. Because of the idea of discontinuity of sustainable power source, the utilization of the auxiliary vitality stockpiling like batteries become essential which can remunerate the fluctuations of power- generator. The alternating current power which is generated is usually has a changing frequency and unsteady voltage, so it has to be change into direct current power. Along with this kind of system, the matter is' whereby to know, when the lead acid cell needs to be charged to give the best efficacy and prolonged life spell. The designed fuzzy supervision is been used to optimized energy share and to choose battery condition of charge parameter. A overseeing scheme supporting fuzzy-control theory has been suggested to attain the peerless result of the lead acid discharging and charging presentation and are balanced with a set up PI controller for execution approval [2]. The control sharing among network

Revised Version Manuscript Received on 10 September, 2019.

S.Vidyasagar, Assistant Professor, Department of Electrical and Electronics, SRM Institute of Science and Technology, Chennai, Tamilnadu, India.

R. Ramya, Assistant Professor, Department of Electrical and Electronics, SRM Institute of Science and Technology, Chennai, Tamilnadu, India.

V.Kalyanasundaram, Assistant Professor, Department of Electrical and Electronics, SRM Institute of Science and Technology, Chennai, Tamilnadu, India. Electronics, SRM Institute of Science and Technology, Chennai, Tamilnadu, India.

Rishikesh Jha UG Student, Department of Electrical and Electronics, SRM Institute of Science and Technology, Chennai, Tamilnadu, India.

Umesh Pratap Sahu, UG Student, Department of Electrical and Electronics, SRM Institute of Science and Technology, Chennai, Tamilnadu, India.

Prachi Naladkar, UG Student, Department of Electrical and Electronics, SRM Institute of Science and Technology, Chennai, Tamilnadu, India.
George Fernandez.S, Assistant Professor, Department of Electrical and

and battery under various operating conditions relies upon the state of charge level of the battery which shows discrete pattern. The proposed technique contributes in the increment of the battery charge/release rates, and amid changes which decreases the battery working time. Hence, in power generation of cell this issue solved by virtual capacitance and virtual resistance drop controller technique, Super-capacitor in direct current miniaturized scale matrix applications. In the designed method of hybrid AC/DC micro-grid control is based on The Adaptive Neural Networks (ANN). The ANN control is tracking the maximum power generated from the limitless energy and exchange of power in the grid. Power amusement in A multi-mode fuzzy logic HESS has been projected. In the given solution, impact of the state of charge (SOC) are usually not taken care of. But still, practical use of multi-mode fuzzy logic strategy is being a challenge. A new power executive's strategy for PV-battery frameworks have been designed in this paper.to provide stable task to sc-pv-battery system, an energy management and control framework has been proposed. It has presented better control technique for a PV-battery framework, which can centre around advancing unique power adjusting. An energy storage with higher density is needed to reimburse for the fragmentary of the inexhaustible energy resources and to buffer out low frequency oscillation, energy storage with higher energy density is needed. This can be achieved by adding super-capacitor [1]. By using a battery super-capacitor hybrid energy stockpiling framework, it enhances the battery and expand the lifetime by maintaining a strategic distance from profound release through high current [2]. The suggested fuzzy-logic-based EMS is been used to line up the power set point of the PV panel which is combined with storage and to optimize the complete operation for the system [3]. For attaining various kind of load requirement, the reaction of an energy source with shows slower dynamic response has to be upgraded by the expansion of a capacitor gadget with quicker dynamics, (for example super-capacitor, batter bank etc) [5]. HESS have been proposed to divergence of excess power, which would otherwise damage the Battery [6]. then micro grid is used under severe load fluctuations, battery will be under high tension and cannot respond on time. It is reflected with increasing charging and releasing cycles and results in high depth of discharge (DOD), ultimately leading to reduced battery lifetime [7]. during the day PV yield power and load request may undergo variable changes. The power micromanagement equation for 
PV-batteries framework are used to deal with the power stream and react to any variation which would keep the balance among power consumption and production [8]. Power management procedures is been proposed for islanded microgrids which incorporate photo-voltaic and battery. These strategies require EMS to access the power measurements at every load node and DG unit [9]
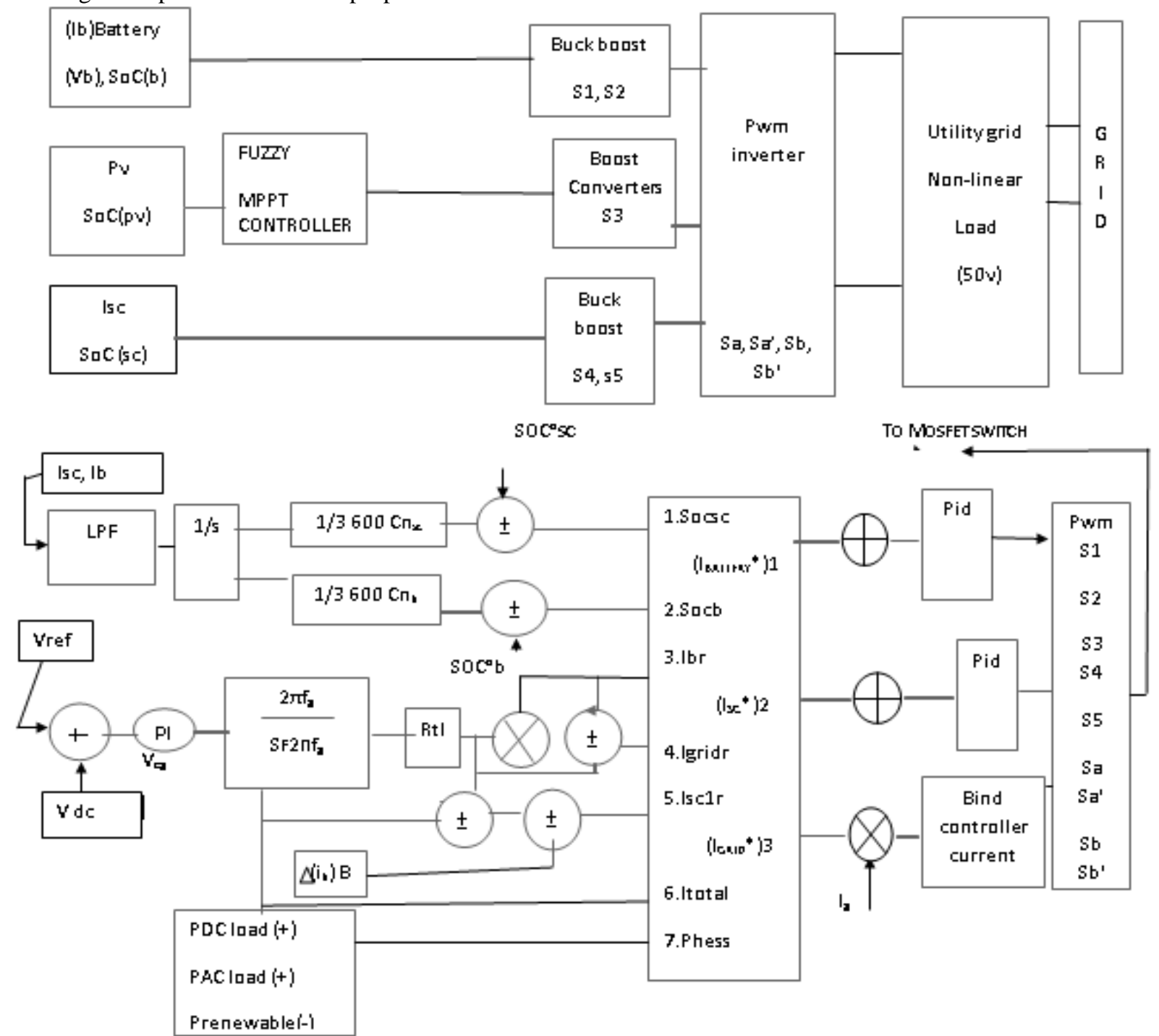

Fig 1. Block diagram of HESS connected to energy management system (EMS)

TABLE I. System parameters for simulation study.

\begin{tabular}{|c|c|}
\hline array parameters STC & Readings \\
\hline Open circuit voltage (vpv) & $40 \mathrm{~V}$ \\
\hline Short circuit current (ipv) & $12 \mathrm{~A}$ \\
\hline Battery particulars & Values \\
\hline $\begin{array}{c}\text { Type } \\
\text { Ah capacity } \\
\text { Terminal Voltage }\left(v_{b}\right) \\
\text { No of b atteries in series }\end{array}$ & $\begin{array}{l}\text { Lead Acid } \\
1.2 \mathrm{Ah} \\
12.5 \mathrm{~V} \\
4\end{array}$ \\
\hline SC specifications & Values \\
\hline $\begin{array}{l}\text { Terminal voltage (vsc) } \\
\text { Capacitance (Csc) } \\
\text { No of } \mathrm{SCs} \text { in } \\
\text { series } \\
\text { Maximum continuous current } \\
\text { Maximum current in } 1 \mathrm{sec}\end{array}$ & $\begin{array}{l}15 \mathrm{~V} \\
58 \mathrm{~F} \\
4 \\
20 \mathrm{~A} \\
80 \mathrm{~A}\end{array}$ \\
\hline Conv erters parameters & $\begin{array}{c}L_{p v}=10 \mathrm{mH}, C_{p v}=420 \mu \mathrm{F} \\
L_{\text {bat }}=1.63 \mathrm{mH}, C_{b}=420 \mu \mathrm{F} \\
L_{\text {scap }}=2 \mathrm{mH}, C_{s}=420 \mu \mathrm{F} \\
C_{\text {dol }}=1600 \mu \mathrm{F}, C_{\text {do }}=1600 \\
\mu \mathrm{F} L_{\mathrm{s}}=5 \mathrm{mH}, C_{r}=15 \mu \mathrm{F} \\
L_{s}=5 \mathrm{mH}\end{array}$ \\
\hline Controller parameters & $\begin{array}{c}k_{a v}=0,1, k_{i \rho v}=1 \\
k_{a b}=0.1, k_{a b}=100 \\
k_{a s c}=0.4, k_{i s c}=150 \\
k_{a s c}=1, k_{a s c}=100 \\
\beta=0.85\end{array}$ \\
\hline Load parameters & $\begin{array}{l}R_{L}=50 \Omega, R_{l c}=20 \Omega \\
R_{n J}=30 \Omega, L_{n l}=50 \mathrm{mH}\end{array}$ \\
\hline
\end{tabular}

\section{EMS MATHEMATICAL MODELING}

In this exhibited paper. An islanded PV-battery-SC hybrid framework is fabricated utilizing a similar setup shown in Fig. 1. The PV panel interfacing with grid by boost converter, Battery and SC interfacing with grid by two buck boost converters, which control PV control and charging/releasing of SC. A non-linearity load is added to bus. The output of converters given as feedback to pid controller which divided by EMS block to PV, Battery, SC respectively. RTL rate limiter reduces current over limit.

\section{A. Battery}

To manage the moderate power request different battery energy storages can be used. In any case, it is unfit to manage high power variance and may experience the ill effects of maturing issue when stressed to high recurrence transient 
power changes. Diverse vitality stockpiling has their distinctive vitality and power densities. Different energy storage has their different energy and power densities. To handle with the described issue, different sequence of energy stockpiling with variable characteristics has been used. One of the best used combinations are of the battery and supercapacitor (SC) structure.

\section{B. Supercapacitors}

The cell-energy-stockpiles has been employed to handle with the slow charging power requirement while the super-capacitor handles the transient power oscillation. the battery along super-capacitor joined hybrid energy stock-piling framework HESS is used extensively in inexhaustible circulated energy production systems. The HESS primarily based on the super-capacitor and battery will effectively clarify the matter of fluctuating power generation and load demand. To increase the life duration, one should avoid overcharging over discharging. Battery along with and ultra-capacitor has been considered as high-density energy storage and huge thickness power stock-piling respectively and their sequence mix has demonstrated to a reliable option. The ultra-capacitor cell hybrid energy storage works better in any condition than battery storage device for photo-voltaic system (Glavine et al). Guojo had demonstrated that battery ultra-capacitor hybrid stock-piling has the excellencies of both immense energy density and huge-power density and such framework enhances battery working time. Dougal and his team had analytically proved that the power and life of battery will be enhanced by battery ultra-capacitor hybrid

\section{C.PV}

Photovoltaic (PV) has become most dominating inexhaustible source generation medium due to its enormous attributes such as torrent of solar and pure energy. Fast PV innovation improvement and decrease in establishment funds are additionally stimulating the expanding organization of $\mathrm{PV}$ in power analysis network. Be that as it may, because of the idea of using solar energy, PV panels, direct power output of a PV system tends to a great extent on its working condition, for example, solar radiance and heat temperature of surrounding, it makes constant change in the output power. To remain output power steady, cell storage systems are usually joined to PV networks to confront the fluctuation problems.

\section{Inverters}

Inverters are needed to coherence the power banks and the supercapacitor to the dc network to maintain the energy flow. The basic necessity from the inverter is to fulfill the load current demand that user should be able to forcefully assign among the cell and the supercapacitor. The various power converter structures are suggested various in the literature for connecting battery and supercapacitor to the dc network. Niemoeller and Krein concluded that a supercapacitor connected to boost converter that are directly joined to the battery, and battery current invisibly is able to concour the sc current. Guidi et al, recommended a way in which supercapacitor is connected to the battery with low power equipment rating. Both the ways have the problem that if it is used for microgrid application, loaf of batteries needed to be connected in series to make a high-voltage dc series network that comes in decline of volumetric adroitness of the battery.

\section{E. Reference Current Generation}

$\mathrm{Pl}(\mathrm{t})-\operatorname{Pren}(\mathrm{t})=\mathrm{Pb}(\mathrm{t})+\operatorname{Psc}(\mathrm{t})+\operatorname{Pg}(\mathrm{t})=\operatorname{Pavg}(\mathrm{t})+\operatorname{Pbtran}(\mathrm{t}) .(1)$ where $\operatorname{Pren}(\mathrm{t}), \operatorname{Pb}(\mathrm{t}), \operatorname{Psc}(\mathrm{t}), \operatorname{Pg}(\mathrm{t})$ and $\mathrm{Pl}(\mathrm{t})$ are the limitless source of energy, battery, Supercapacitor, grid and total load power respectively. Pavg (t) and Pbtran (t) represents the total average power and transient power capacity that provided or taken from the HESS and the utility grid ,to manage the total power balance in the DC link network.

Itot $(t)=$ Kpdc $($ Vref - Vdc $)+$ Kidc int $($ Vref - Vdc $) d t(2)$

Where, Kpdc and Kidc are proportional and integral dc constant in (PI) controller of the total voltage generated.

Iavg $=(2 * \pi * \mathrm{Fcf} /(\mathrm{s}+2 * \pi * \mathrm{Fcf})) *$ Itot.

$\operatorname{Ib}, \mathrm{r}(\mathrm{s})=\gamma \cdot \operatorname{Iavg}(\mathrm{s}), \quad \operatorname{Ig}, \mathrm{r}(\mathrm{s})=(1-\gamma) \cdot \operatorname{Iavg}(\mathrm{s})$

Where Fcf, Ib.r(s), Ig.r(s) and $\gamma$ are the cut-off frequency of the Low Pass Filter(LPF), the current of the battery converter control and the current of the grid and sharing coefficient respectively. The cut-off frequency is set as $5 \mathrm{~Hz}$. [8]

$\gamma=\mathrm{P} 1 .(\mathrm{SOCb})^{\wedge} 4+\mathrm{P} 2 .(\mathrm{SOCb})^{\wedge} 3+\mathrm{P} 3 .\left((\mathrm{SOCb})^{\wedge} 2+\mathrm{P} 4 . \mathrm{SOCb}\right.$

$+\mathrm{P} 5 .(\mathrm{SOCb})^{\wedge} 5$

where, $\mathrm{P} 1=-2.143, \mathrm{P} 2=2.429, \mathrm{P} 3=0.7071, \mathrm{P} 4=0.09286$ and $\mathrm{P} 5=1.832 \mathrm{e}-16$.

TABLE II

Conditions For Dpm

\begin{tabular}{|c|c|}
\hline Conditions & Current setting \\
\hline$S O C_{b}>L_{b} \& S O C_{s c}>L_{s c}$ & $\begin{array}{c}i_{b}^{*}=\gamma \cdot i_{a v g}, i_{s c}^{*}=i_{s c, r} \\
i_{g}^{\prime}=(1-\gamma) \cdot i_{a v g}\end{array}$ \\
\hline$S O C_{b}<L_{b} \& S O C_{s c}>L_{s c}$ & $\begin{array}{c}i_{b}^{\prime}=0, i_{s c}^{\prime}=i_{s c, r} \\
i_{g=i_{a v g}}^{*}\end{array}$ \\
\hline$S O C_{b}>L_{b} \& S O C_{s c}<L_{s c}$ & $\begin{array}{c}i_{b}^{\prime}=\gamma \cdot i_{a v g}, i_{s c}^{*}=0 \\
i_{q}^{\prime}=(1-\gamma) \cdot i_{a v g}+i_{s c, r} \\
i_{b}^{\prime}=0, i_{s c}^{\prime}=0 \\
i_{g}^{\prime}=i_{a v g}+i_{s c, r}\end{array}$ \\
\hline$S O C_{b}<L_{b} \& S O C_{s c}<L_{s c}$ & $i^{*}$ \\
\hline
\end{tabular}

The designed EMS fulfill the following aims:

(i)it restrains the $\mathrm{SOCb}$ and SOCsc between their safe working region, i.e., higher(H) and lower(L) settled SOC limits, (ii)it restricts battery span by the charge and discharge and (iii) it procure seamless mode conversion in the different modes of operating. (iv) reduces pressure on the battery and increase lifespan of the cel, and (v) estimate low profound. [10]

The error is sent to the PI controller current side that generates a duty ratio. Duty ratio triggers the pulse current and regulates in circuit. The rate limiter (RTL) works with LPF and restrains the rate of charge/release of the battery below suggested higher limit value.

The transient and regulatory component in the total current reference is given by (6),

$\mathrm{Isc}, \mathrm{r}=\operatorname{Itran}(\mathrm{s})=(1-(2 * \pi * \mathrm{Fcf} / \mathrm{s}+2 * \pi * \mathrm{Fcf})) *(\operatorname{Itot}+$ $\beta \Delta \mathrm{ib})$.

In (6), Isc, $\mathrm{r}$ and $\Delta \mathrm{ib}$ are the SC reference current and the unrecompensed current in the battery .

Here $\beta=(\mathrm{Vb} / \mathrm{Vsc})$ is the compensation factor. [7] 


\section{F. Proposed EMS}

In this proposed EMS two modes of operation are suggested, (i) excess power mode (EPM) (ii) deficit power mode (DPM). The two modes of working condition are determined in block dig. This conditions are based on the limitless power creation and the load bidding in the EMS system. That they are deficit power mode (Phess $>0$ ) and excess power mode (Phess $<=0$ ) where Phess $=\mathrm{Pb}+\mathrm{Psc}+\mathrm{Pg}=$ Pdcl+Pacl-Pren.

$\mathrm{SOCb}=\mathrm{SOC} 0 \mathrm{~b}-1 /(3600 . \mathrm{Cnb} \mathrm{Z}) \operatorname{int}(\mathrm{Ib} \mathrm{dt})$

SOCsc $=$ SOC0sc $-1 /(3600$. Cnb Z $)$ int $($ Isc dt $)$

where SOCOb, SOCOsc, Cnb and Cnsc are start SOCs of cell and SC, bulk of the battery and SC respectively. [4]

TABLE III

Conditions For Ems

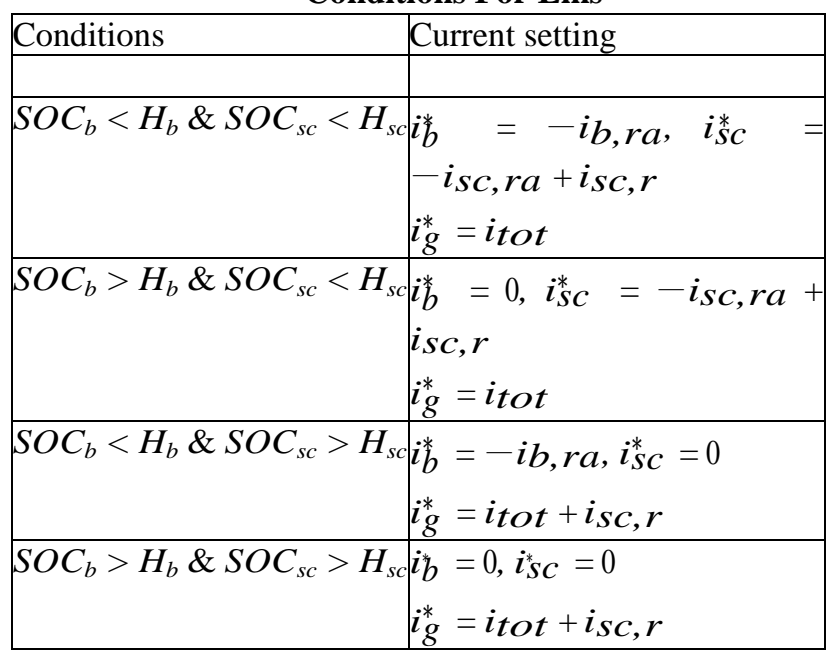

\section{III.EMS SCHEME}

In the designed method the two-mode built control is used to attain the maximum power from the renewable feeders so that it interchanges power from the grid system network. As the load in the battery system increases the battery balances the $\mathrm{DC}$ and $\mathrm{AC}$ power in all networks.

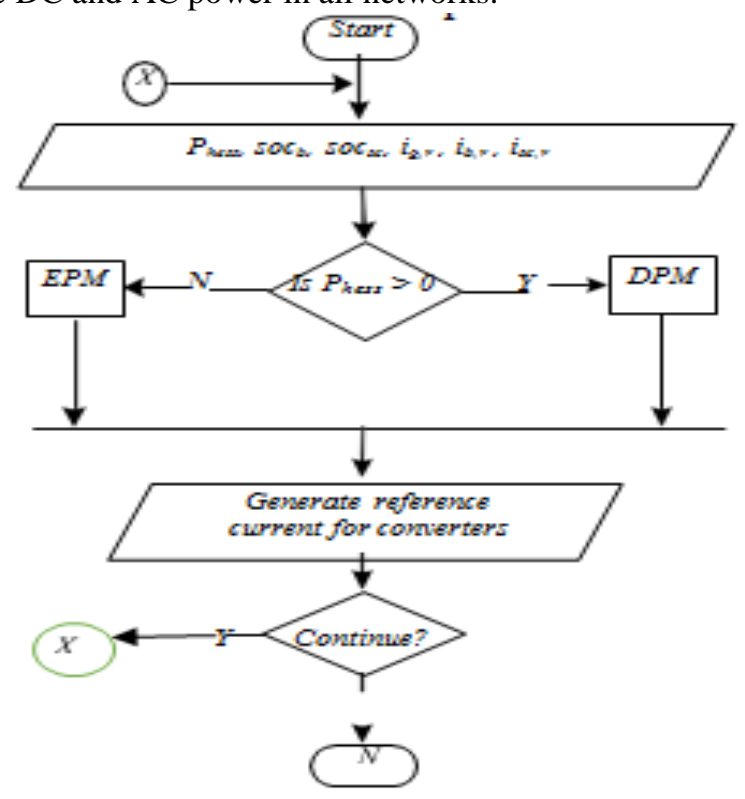

Fig 2. Plan for EMS-(i) Excess Power Mode (EPM) and (ii) Deficit Power Mode (DPM)
Due to excess load it harms the battery hence it reduces the lifespan of the cell that makes structure of sell complected this resulting in the cost of battery which rises to meet peak load request. All this happens because of virtual opposition and virtual capacitance droop controller. Power generation in lead cell and SC is managed by droop controller for use of DC micro gird .Smooth power flow between the energy storage and the DC network system is managed by bidirectional half bridge DC-DC chopper connected to HESS system. [3]

\section{FUZZY CONTROL}

A fuzzy control scheme is predicted by symbolic logic thinking within the style of however a controller operates. Therefore, assigned as symbolic logic is to determine a buffer zone between the ideal zero and one, when logic statement of nonzero and non-one possible.this has vast limits and more adjustable space in logic hypothesis which manifests new and various indefinite ideas and experience. A fuzzy controller is not an ideal controller it has variations that needs to set a some set of constrain rules determined by Fuzzy control theory settled in illustration is applied in the HESS system to achieve the smooth running of the network. With switching on and off the batteries the fuzzy logic controller works effectively.

Simulation results were procured by developing a in depth dynamic hybrid system protypical. From simulation result, the network gains power smoothness, and the cell SOC deals with the needed an inducement to increase span of battery life. When fuzzy controller is in charging mode or releasing mode the required SOC has set idealy for the suggested hybrid system [5]. The set of $4 * 4$ interpreted values are channelized to deliver stabilized irradiance constant of 1000 $\mathrm{rad} / \mathrm{m} 2$. The fuzzy logic controller is located near the PV panel. There are a significant huge number of explores actualizing fuzzy logic in the energy executive's framework [5]. It is by all accounts exceptionally proper since it decides the condition as in a state. The capacity to decide the yield dependent on a condition is the thing that makes it adaptable, settling on it near human choice. It works dependent on lingual 'if. at that point' rules [6] and considering vulnerabilities that generally acquire while deciding output, fuzzy logic is viewed as sensible and rationale. In this paper, fuzzy rationale controller is utilized as hybrid electric vehicle for the energy management framework. So as to decide the conditions, the information and yield factors must be confirmed first. In preceding the structure of the fuzzy logic controller three stages are present that should be solved before getting output.

These three phases are (1) fuzzification, (2) inference, and (3) defuzzification. Fuzzification is the process of creating fuzzy sets, in this process the input and outputs are determined, as well as membership functions are formed. Inference is the 2nd stage in this stage some constraints are generated according to the input and output variables. Some of the fuzzy strategies utilized in this fuzzy logic controller are similar as in simulation FIS file. Defuzzification is the 
way toward making a solitary crisp to represent the fuzzy sets. The yield factors in this examination would be the choice of intensity from either cell or supercapacitor dependent on specific conditions. (1) battery control (bat) and (2) supercapacitor control (SC). Fuzzy is powerful and comparatively straightforward to style since fuzzy don't need info regarding the precise model [4].

The PV power at the present at time will be judged with the $\mathrm{PV}$ power at the initial state and one of the input will be the change in power of fuzzy. Another input will be change of power with relevance to change in voltage. Based on these two inputs, fuzzy will confirm the dimensions of perturbed voltage. In this manner, MPPT framework dependent on fuzzy logic can follow the most extreme power point quicker.

\section{HARDWARE COMPONENETS}

\section{TABLE 4. Recquired Components}

\begin{tabular}{|l|l|l|l|}
\hline SI no. & $\begin{array}{l}\text { Component } \\
\text { s }\end{array}$ & Ratings & Cost $\square$ \\
\hline 1 & Capacitor & $1000 \mathrm{nf} / 50 \mathrm{v}$ & $10(10)=100$ \\
\hline 2 & Inductor & $2.5 \mathrm{mh}$ & $220(4)=880$ \\
\hline 3 & MOSFET & 1 RF840N & $220(9)=1980$ \\
\hline 4 & Controller & Dspic 30f20 & 1196 \\
\hline 5 & $\begin{array}{l}\text { Pwm } \\
\text { generator }\end{array}$ & TLP 250 & 412 \\
\hline 6 & Battery & $12 \mathrm{v} / 1.3 \mathrm{Ah}$ & $45(4)=180$ \\
\hline 7 & PV panel & $5 \mathrm{w}$ & 1500 \\
\hline (i) & Vos V & $217 \mathrm{~V}$ & \\
\hline (ii) & Vss V & $21.6 \mathrm{~V}$ & \\
\hline (iii) & IOS V & $0.327 \mathrm{~V}$ & \\
\hline (iv) & Irradiance & 1000 & \\
& & & \\
& TOTAL & & \\
& Wire connection & & \\
\end{tabular}

\section{RESULTS AND DISCUSSIONS}

There is two expected results of simulation and hardware respectively. In simulation, the outcome is shown with and without the effect of fuzzy logic implementation. The $\mathrm{o} / \mathrm{p}$ voltage $(50 \mathrm{v})$ average is being stabilise through dc source by using voltage source inverter (VSI). In the given table no 5, the specification of the terminology like Power, Current, Voltage and Form factor of $\mathrm{PV}\left(\mathrm{P}_{\mathrm{PV}}\right)$, Supercapacitance and Battery is determined along with the grid rms voltage $\left(\mathrm{V}_{\mathrm{rms}}\right)$ and current $\left(\mathrm{I}_{\mathrm{rms}}\right)$. The manual calculation states that power of the dc voltage grid is 1600 watts. The net total current $\left(\mathrm{I}_{\text {tot }}(\mathrm{t})\right)$ of in overall grid is important factor to determine as required by the scheme to estimate EPM and DPM conditions.
TABLE 5. Experiment test result

\begin{tabular}{|l|l|l|}
\hline $\mathrm{P}_{\mathrm{PV}}$ & $\mathrm{I}^{*} \mathrm{~V}$ & $800 \mathrm{w}$ \\
\hline $\mathrm{PB}$ & $\mathrm{I}^{*} \mathrm{~V}$ & $586 \mathrm{w}$ \\
\hline $\mathrm{P}_{\mathrm{sc}}$ & $\mathrm{I}^{*} \mathrm{~V} \mathrm{n}$ & 1200 \\
\hline $\mathrm{I}_{\text {tot }}(\mathrm{t})$ & $\begin{array}{l}\text { Kpdc }(\text { Vref }-\mathrm{Vdc})+ \\
\text { Kidc Z(Vref }-\mathrm{Vdc}) \mathrm{dt}\end{array}$ & $330 \mathrm{~A}$ \\
\hline $\mathrm{I}_{\mathrm{avg}}$ & $\begin{array}{l}\left(2 * \pi^{*} \mathrm{f}_{\mathrm{cf}} /\left(\mathrm{s}+2^{*} \pi^{*} \mathrm{f}_{\mathrm{cf}}\right)\right)^{*} \mathrm{i}_{\mathrm{t}} \\
\text { ot }\end{array}$ & $10 \pi /(\mathrm{s}+10 \pi)$ \\
\hline $\mathrm{I}_{\mathrm{dc}}$ & $\mathrm{I}^{*} \mathrm{~V}$ & $1600 \mathrm{~W}$ \\
\hline $\mathrm{V}_{\mathrm{rms}}$ & $\mathrm{V}_{\text {peak }} / \sqrt{2}$ & 56.57 \\
\hline $\mathrm{I}_{\mathrm{rms}}$ & $\mathrm{I}_{\text {peak }} / \sqrt{2}$ & 28.28 \\
\hline $\begin{array}{l}\text { Form } \\
\text { factor }\end{array}$ & $\mathrm{V}_{\text {rms } /} \mathrm{V}_{\text {avg }}$ & 1.11 \\
\hline
\end{tabular}

\section{A. Simulation Results}

The simulation of the EMS scheme is just unaffected by the Mppt controller. The simulation shown in Fig-3 is 50v grid voltage which is unaffected as per the requirement.

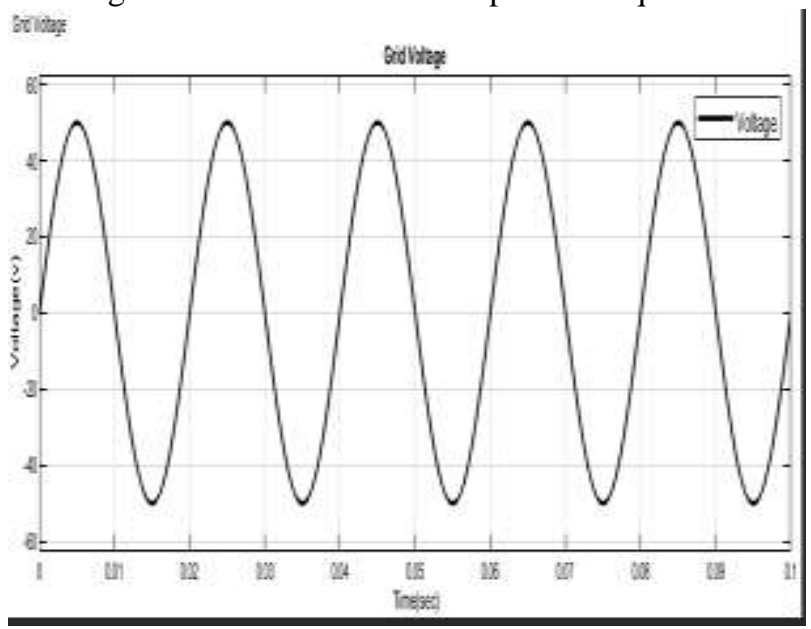

Fig 3. Supply Grid voltage

The next Fig-4 is the utility grid voltage which is stabilized around 50 volts due to EPM and DPM condition. The supply $\mathrm{dc}$ voltage of battery is varied between $45 \mathrm{v}$ to $55 \mathrm{v}$.

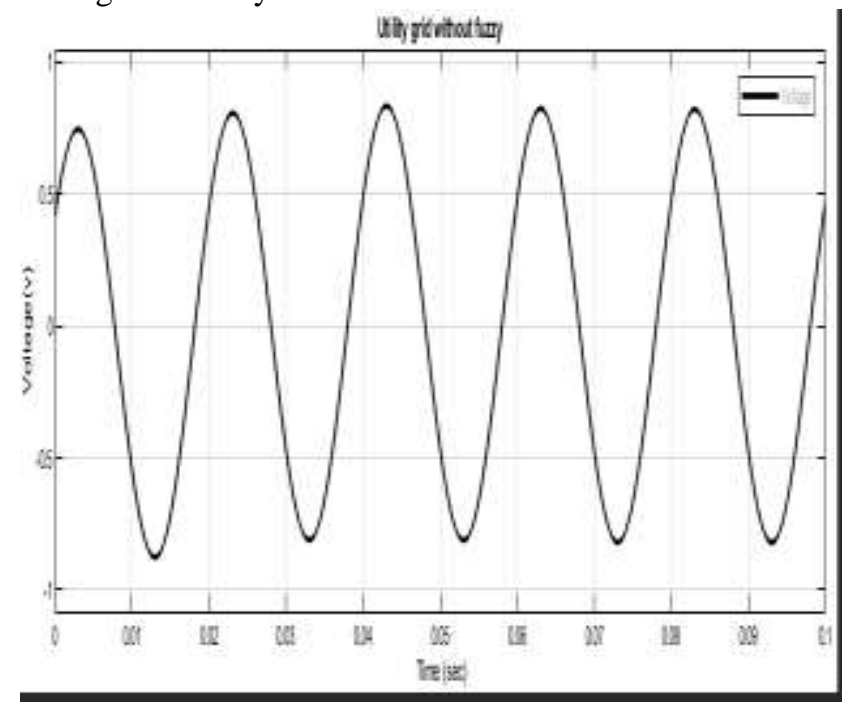

Fig 4. Utility Grid voltage for nonlinear load 
The third simulation of Fig-5 is represented as the utility grid voltage of the EMS which have dynamic and Mppt controlled power sharing voltage. With the fuzzy logic code implementation in the member function of controller, the output result is stabilized and maximized with the input source depending upon the fluctuation in Pv source panel. This graph shows that the maximum output is achieved by energy management system. By this method we can improvise automated precision with efficiency and accuracy. The input source is fed between $45 \mathrm{v}$ to 55 volts.

The simulation output is also measurable at each device. Thus, the pulse triggering is malleable with condition applied in EMS block. The closed loop of EMS scheme through fuzzy logic implementation is achieved.

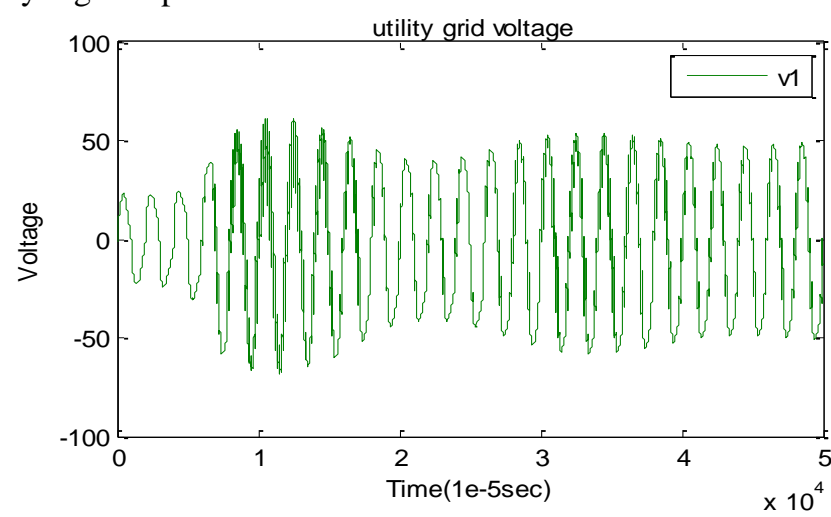

Fig 5. Fuzzy Logic Implementation Over EMS.

\section{VII.HARDWARE IMPLEMENTATION}

Above given picture is a hardware implementation of open loop EMS structure fed to the microgrid or in applications of electrical vehicle. As shown in fig 5 hardware is subdivided into 4 blocks, top left contains converters, top right is inverter, bottom left block contains driver circuits which triggers gate pulses for the mosfets, left out block is the main processing unit of EMS. The microcontroller DSPICIR2W10 amplifies the voltage according to conditions of EPM AND DPM method. Battery, PV, SC are input sources to the converters. For $12.7 \mathrm{~V}$ battery input give satisfying output to lamp load of $24.7 \mathrm{~V}$.

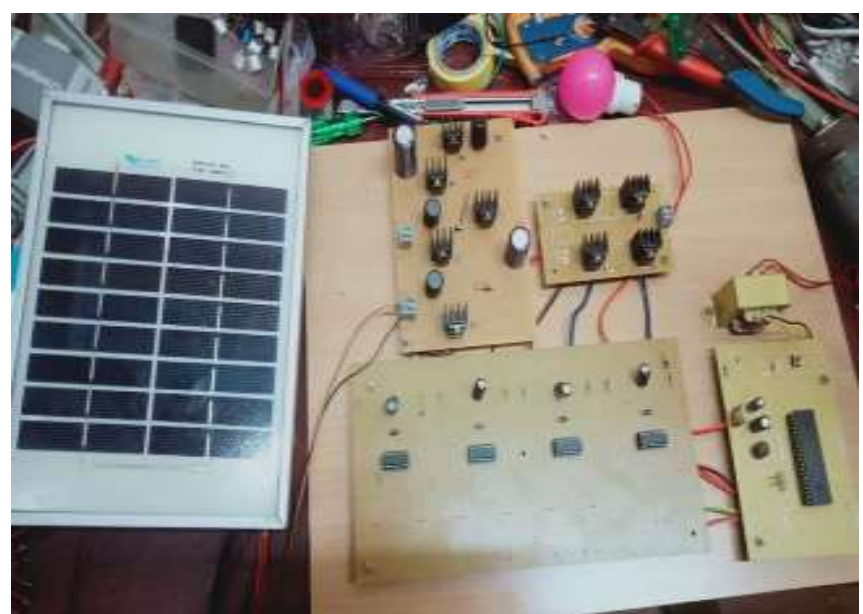

Fig 5. Hardware Picture of Energy Management System.

\section{VIII.CONCLUSIONS}

The result of the simulation and hardware components provide sustainable backup with dependable outcome power required. It satisfies the optimal energy flow through the load and manage in more efficient way. The output of fuzzy implemented EMS logic is stabilizing around $50 \mathrm{~V}$.

The simulation is designed in a way outcome will be $50 \mathrm{~V}$ to any variable voltage. [6] Future scope on further implementation of closed loop feedback-controlled EMS system using fuzzy logic in hardware segment part is required.

\section{REFERENCES}

1 H. Zhou, T. Bhattacharya, D. Tran, T. S. T. Siew, and A.M. Khammbad- kone, "Composite energy storage system involving battery and ultraca- pacitor with dynamic energy management in microgrid applications," IEEE Trans. Power. Electron., vol. 26, no. 2, pp. 923-930, Mar. 2011.

2 M. E. Glavin, P. K. W. Chan, S. Armstrong, and W. G. Hurley, "A stand- alone photovoltaic supercapacitor battery hybrid energy storage system," in 13th International Power Electron. and Motion Control Conf., Sept. 2008, pp. 1688-1695.

3 J. Pegueroles-Queraelt, F. D. Bianchi, and O. Gomis-Bellmunt, "A power smoothing system based on supercapacitors for renewable distributed generation," IEEE Trans. Ind. Electron., vol. 61, no. 1, pp. 343-350, Jan. 2015.

4 P.Ciradeja and R.Ramakumar. 2004. An approach to quantify the technical benefits of distributed generation. IEEE Trans. Energy Convers, vol. 19, no.6, pp. 764-773, Dec. 2012

5 M.H.Nehreer, C.Wang, K.Strunz, H.Akee, R.Ramakumar, J. Bing, Z. Miao, and Z. Salameh. 2011. An audit of hybrid inexhaustible/elective vitality systems for electric power generation: Configurations, control, and applications. IEEE Trans. Sustain. Energy, vol. 2, no.34, pp. 392-403, October.2017

6 L. Sun, K. Feng, C. Chapman, and N. Zhang, "A versatile power-split system for battery, supercapacitor powertrain, plan, simulation, and experiment," IEEE Trans. Power. Electron., vol. 32, no. 12, pp. 9364-9375, Dec. 2017.

7 R. Sathish Kumar, S. K. Kollimalla, and M. K. Mishra, "Dynamic energy management of micro grids utilizing battery super capacitor consolidated capacity." in Annual IEEE India Conf. (INDICON), Dec. 2012, pp. 10781083.

8 Z. Yee, W. Dong, and A. H. Etemadi, "A unified control and power management scheme for pv-battery-based hybrid microgrids for both grid-connected and islanded modes," IEEE Trans. Smart. Grid, vol. PP, no. 98, pp. $1-1,2017$.

9 H. Mahmood, D. Meechaelson, and J. Ziang, "A power management plan for pv/battery hybrid systems in islanded microgrids," IEEE Jour. Emerg. and Sel. Topics in Power Electron., vol. 2, no. 4, pp. 870-882, Dec. 2014

10 D. B. W. Abiywardana, B. Hredzak, and V. G. Agelidis, "A fixed recurrence sliding mode controller for a boost inverter-based battery supercapacitor hybrid energy stockpiling framework," IEEE Trans. Power. Electron., vol. 32, no. 1, pp. 668-680, Jan. 2017. 